\title{
Tree-Antimagicness of Disconnected Graphs
}

\author{
Martin Bača, ${ }^{1}$ Zuzana Kimáková, ${ }^{1}$ Andrea Semaničová-Feňovčíková, ${ }^{1}$ \\ and Muhammad Awais Umar ${ }^{2}$ \\ ${ }^{1}$ Department of Applied Mathematics and Informatics, Technical University, 04200 Košice, Slovakia \\ ${ }^{2}$ Abdus Salam International Center of Mathematics, Information Technology University, Lahore, Pakistan
}

Correspondence should be addressed to Martin Bača; martin.baca@tuke.sk

Received 10 October 2014; Accepted 5 January 2015

Academic Editor: Qing-Wen Wang

Copyright (C) 2015 Martin Bača et al. This is an open access article distributed under the Creative Commons Attribution License, which permits unrestricted use, distribution, and reproduction in any medium, provided the original work is properly cited.

\begin{abstract}
A simple graph $G$ admits an $H$-covering if every edge in $E(G)$ belongs to a subgraph of $G$ isomorphic to $H$. The graph $G$ is said to be $(a, d)$ - $H$-antimagic if there exists a bijection from the vertex set $V(G)$ and the edge set $E(G)$ onto the set of integers $\{1,2, \ldots,|V(G)|+$ $|E(G)|\}$ such that, for all subgraphs $H^{\prime}$ of $G$ isomorphic to $H$, the sum of labels of all vertices and edges belonging to $H^{\prime}$ constitute the arithmetic progression with the initial term $a$ and the common difference $d$. $G$ is said to be a super $(a, d)$ - $H$-antimagic if the smallest possible labels appear on the vertices. In this paper, we study super tree-antimagic total labelings of disjoint union of graphs.
\end{abstract}

\section{Introduction}

We consider finite undirected graphs without loops and multiple edges. The vertex and edge set of a graph $G$ are denoted by $V(G)$ and $E(G)$, respectively. An edge-covering of $G$ is a family of subgraphs $H_{1}, H_{2}, \ldots, H_{t}$ such that each edge of $E(G)$ belongs to at least one of the subgraphs $H_{i}, i=1,2, \ldots, t$. In this case we say that $G$ admits an $\left(H_{1}, H_{2}, \ldots, H_{t}\right)$-(edge) covering. If every subgraph $H_{i}$ is isomorphic to given graph $H$, then the graph $G$ admits an $H$-covering. A bijective function $f: V(G) \cup E(G) \rightarrow\{1,2, \ldots,|V(G)|+|E(G)|\}$ which we call a total labeling and the associated $H$-weight of subgraph $H$ is $w t_{f}(H)=\sum_{v \in V(H)} f(v)+\sum_{e \in E(H)} f(e)$. An $(a, d)-H-$ antimagic total labeling of graph $G$ admitting an $H$-covering is a total labeling with the property that, for all subgraphs $H^{\prime}$ isomorphic to $H$, the $H^{\prime}$-weights form an arithmetic progression $a, a+d, a+2 d, \ldots, a+(t-1) d$, where $a>0$ and $d \geq 0$ are two integers and $t$ is the number of all subgraphs of $G$ isomorphic to $H$. Such a labeling is called a super if the smallest possible labels appear on the vertices. A graph that admits a (super) $(a, d)-H$-antimagic total labeling is called a (super) $(a, d)$-H-antimagic. For $d=0$, it is called $H$-magic and $H$-supermagic, respectively.

The $H$-(super)magic labelings were first studied by Gutiérrez and Lladó [1]. These labelings are the generalization of the edge-magic and super edge-magic labelings that were introduced by Kotzig and Rosa [2] and Enomoto et al. [3], respectively. For further information about (super) edgemagic labelings, one can see [4-8]. Gutiérrez and Lladó [1] proved that certain classes of connected graphs are $H$ (super)magic, such as the star $K_{1, n}$ and the complete bipartite graphs $K_{n, m}$ are $K_{1, h}$-supermagic for some $h$. They also proved that the cycle $C_{n}$ is $P_{h}$-supermagic for any $2 \leq h \leq n-1$ such that $\operatorname{gcd}(n, h(h-1))=1$. Lladó and Moragas [9] studied the cycle-(super)magic behavior of several classes of connected graphs. They proved that wheels, windmills, books, and prisms are $C_{h}$-magic for some $h$. Maryati et al. [10] and also Salman et al. [11] proved that certain families of trees are path-supermagic. Ngurah et al. [12] proved that chains, wheels, triangles, ladders, and grids are cycle-supermagic.

The $(a, d)-H$-antimagic total labeling is introduced by Inayah et al. [13]. In [14], the super $(a, d)-H$-antimagic labelings are investigated for some shackles of connected graph $H$.

When $H$ is isomorphic to $K_{2}$, a super $(a, d)-K_{2}$-antimagic total labeling is also called super $(a, d)$-edge-antimagic total. The notion of $(a, d)$-edge-antimagic total labeling was introduced by Simanjuntak et al. in [15] as a natural extension of the edge-magic labeling defined by Kotzig and Rosa in [2] as magic valuation.

The (super) $(a, d)-H$-antimagic total labeling is related to a super $d$-antimagic labeling of type $(1,1,0)$ of a plane graph. 
A labeling of type $(1,1,0)$, that is, a total labeling, of a plane graph is said to be $d$-antimagic if for every positive integer $s$ the set of weights of all $s$-sided faces is $W_{s}=\left\{a_{s}, a_{s}+d, a_{s}+\right.$ $\left.2 d, \ldots, a_{s}+\left(f_{s}-1\right) d\right\}$ for some integers $a_{s}>0$ and $d \geq 0$, where $f_{s}$ is the number of the $s$-sided faces. Note that there are allowed different sets $W_{s}$ for different $s$. The weight of a face under a labeling of type $(1,1,0)$ is the sum of labels of all the edges and vertices surrounding that face. If $d=0$, then Lih [16] calls such labeling magic and describes magic (0-antimagic) labelings of type $(1,1,0)$ for wheels, friendship graphs, and prisms. In [17], Ahmad et al. investigate the existence of super $d$-antimagic labelings of type $(1,1,0)$ for disjoint union of plane graphs for several values of difference $d$.

In this paper we mainly investigate the existence of super $(a, 1)$-tree-antimagic total labelings for disconnected graphs. We concentrate on the following problem: if graph $G$ admits a (super) $(a, 1)$-tree-antimagic total labeling, does the disjoint union of $m$ copies of the graph $G$, denoted by $m G$, admit a (super) $(b, 1)$-tree-antimagic total labeling as well?

\section{Super $(a, 1)$-Tree-Antimagic Total Labeling}

In this section, we will study the super $(a, 1)$-tree-antimagicness for disconnected graphs. The main result is the following.

Theorem 1. Let $m, t \geq 1$ be positive integers. Let $G_{i}$ with a $\left(T_{i}^{1}, T_{i}^{2}, \ldots, T_{i}^{t}\right)$-covering be a super $(a, 1)$-T-antimagic graph of order $p$ and size $q, i=1,2, \ldots, m$, where $T$ is a tree and every tree $T_{i}^{j}, j=1,2, \ldots, t$, is isomorphic to $T$. Then the disjoint union $\bigcup_{i=1}^{m} G_{i}$ is also a super $(b, 1)$-T-antimagic graph.

Proof. Let $m \geq 1$ and $t \geq 1$ be positive integers and let $T$ be a tree of order $k$. Let $G_{i}, i=1,2, \ldots, m$, be a graph with $p$ vertices and $q$ edges that admits a $\left(T_{i}^{1}, T_{i}^{2}, \ldots, T_{i}^{t}\right)$-covering. Note that $G_{i}$ is not necessarily isomorphic to $G_{j}$ for $i \neq j$. Assume that every $G_{i}, i=1,2, \ldots, m$, has a super $(a, 1)-T$ antimagic total labeling $f_{i}: V\left(G_{i}\right) \cup E\left(G_{i}\right) \rightarrow\{1,2, \ldots, p\} \cup$ $\{p+1, p+2, \ldots, p+q\} ;$ thus

$$
\left\{w t_{f_{i}}\left(T_{i}^{j}\right): j=1,2, \ldots, t\right\}=\{a, a+1, \ldots, a+t-1\}
$$

is the set of the corresponding $T_{i}^{j}$-weights, where every tree $T_{i}^{j}, j=1,2, \ldots, t$, is isomorphic to $T$.

Define the labeling $f$ for the vertices and edges of $\bigcup_{i=1}^{m} G_{i}$ in the following way:

$$
f(x)= \begin{cases}m\left(f_{i}(x)-1\right)+i, & \text { if } x \in V\left(G_{i}\right), \\ m f_{i}(x)+1-i, & \text { if } x \in E\left(G_{i}\right) .\end{cases}
$$

First we will show that the vertices of $\bigcup_{i=1}^{m} G_{i}$ under the labeling $f$, use integers from 1 up to $p m$; that is, if $i=1$, then the vertices of $G_{1}$ successively attain values $[1, m+1,2 m+$ $1, \ldots,(p-1) m+1]$, if $i=2$, then the vertices of $G_{2}$ successively assume values $[2, m+2,2 m+2, \ldots,(p-1) m+2], \ldots$, the values of vertices of $G_{i}$ are equal successively to $[i, m+i, 2 m+$ $i, \ldots,(p-1) m+i], \ldots$, and if $i=m$, then the vertices of $G_{m}$ successively assume values $[m, 2 m, 3 m, \ldots, p m]$.
Second we can see that the edges of $\bigcup_{i=1}^{m} G_{i}$ under the labeling $f$ use integers from $p m+1$ up to $(p+q) m$. It means that if $i=1$, then the edges of $G_{1}$ successively assume values $[(p+1) m,(p+2) m,(p+3) m, \ldots,(p+q) m]$, if $i=2$, then the edges of $G_{2}$ successively attain values $[(p+1) m-1,(p+2) m-1$, $(p+3) m-1, \ldots,(p+q) m-1], \ldots$, the values of edges of $G_{i}$ are equal successively to $[(p+1) m+1-i,(p+2) m+1-i$, $(p+3) m+1-i, \ldots,(p+q) m+1-i], \ldots$, and if $i=m$, then the edges of $G_{m}$ successively attain values $[p m+1,(p+1) m+1$, $(p+2) m+1, \ldots,(p+q-1) m+1]$.

It is not difficult to see that the labeling $f$ is a bijective function which assigns the integer $\{1,2, \ldots,(p+q) m\}$ to the vertices and edges of $\bigcup_{i=1}^{m} G_{i}$; thus $f$ is a total labeling.

For the weight of every subgraph $T_{i}^{j}$ isomorphic to the tree $T$ under the labeling $f$, we have

$$
\begin{aligned}
w t_{f}\left(T_{i}^{j}\right)= & \sum_{v \in V\left(T_{i}^{j}\right)} f(v)+\sum_{e \in E\left(T_{i}^{j}\right)} f(e) \\
= & \sum_{v \in V\left(T_{i}^{j}\right)}\left(m\left(f_{i}(v)-1\right)+i\right) \\
& +\sum_{e \in E\left(T_{i}^{j}\right)}\left(m f_{i}(e)+1-i\right) \\
= & m \sum_{v \in V\left(T_{i}^{j}\right)} f_{i}(v)-m\left|V\left(T_{i}^{j}\right)\right|+i\left|V\left(T_{i}^{j}\right)\right| \\
& +m \sum_{e \in E\left(T_{i}^{j}\right)} f_{i}(e)+\left|E\left(T_{i}^{j}\right)\right|-i\left|E\left(T_{i}^{j}\right)\right| \\
= & m\left(\sum_{v \in V\left(T_{i}^{j}\right)} f_{i}(v)+\sum_{e \in E\left(T_{i}^{j}\right)} f_{i}(e)\right. \\
& +m\left|V\left(T_{i}^{j}\right)\right|+\left|E\left(T_{i}^{j}\right)\right|+i\left|V\left(T_{i}^{j}\right)\right|-i\left|E\left(T_{i}^{j}\right)\right| \\
= & m w t_{f_{i}}\left(T_{i}^{j}\right)-m\left|V\left(T_{i}^{j}\right)\right|+\left|E\left(T_{i}^{j}\right)\right| \\
& +i\left|V\left(T_{i}^{j}\right)\right|-i\left|E\left(T_{i}^{j}\right)\right| \cdot \\
& \\
& m
\end{aligned}
$$

As every $T_{i}^{j}, i=1,2, \ldots, m, j=1,2, \ldots, t$, is isomorphic to the tree $T$, it holds

$$
\begin{gathered}
\left|V\left(T_{i}^{j}\right)\right|=|V(T)|=k, \\
\left|E\left(T_{i}^{j}\right)\right|=|E(T)|=|V(T)|-1=k-1 .
\end{gathered}
$$

Thus for the $T$-weights we get

$$
w t_{f}\left(T_{i}^{j}\right)=m w t_{f_{i}}\left(T_{i}^{j}\right)+k(1-m)-1+i .
$$

According to (1), we get that the $T$-weights in components are the following:

if $i=1$, then the $T_{1}^{j}$-weights in $G_{1}$ are $m(a-k)+k$, $m(a-k+1)+k, \ldots$, and $m(a-k+t-1)+k$; 
if $i=2$, then the $T_{2}^{j}$-weights in $G_{2}$ are $m(a-k)+k+1$, $m(a-k+1)+k+1, \ldots$, and $m(a-k+t-1)+k+1$;

if $i=3$, then the $T_{3}^{j}$-weights in $G_{3}$ are $m(a-k)+k+2$, $m(a-k+1)+k+2, \ldots$, and $m(a-k+t-1)+k+2$;

if $i=m-1$, then the $T_{m-1}^{j}$-weights in $G_{m-1}$ successively attain values $m(a-k)+k+m-2$, $m(a-k+1)+k+m-2, \ldots$, and $m(a-k+t-1)+k+m-2$;

if $i=m$, then the $T_{m}^{j}$-weights in $G_{m}$ successively assume values $m(a-k)+k+m-1, m(a-k+1)+k+m-1$, $\ldots$, and $m(a-k+t-1)+k+m-1$.

It is easy to see that the set of all $T$-weights in $\bigcup_{i=1}^{m} G_{i}$ consists of distinct and consecutive integers:

$$
\begin{aligned}
\left\{w t_{f}\right. & \left.\left(T_{i}^{j}\right): i=1,2, \ldots, m ; j=1,2, \ldots, t\right\} \\
= & \{m(a-k)+k, m(a-k) \\
& +k+1, \ldots, m(a-k+t)+k-1\} .
\end{aligned}
$$

Thus the graph $\bigcup_{i=1}^{m} G_{i}$ is a super $(m(a-k)+k, 1)-T$ antimagic.

Immediately from the previous theorem we get that arbitrary number of copies of a super $(a, 1)$ - $T$-antimagic graph is a super $(b, 1)$ - $T$-antimagic.

Corollary 2. Let $G$ be a super ( $a, 1)$-T-antimagic graph, where $T$ is a tree. Then the disjoint union of arbitrary number of copies of $G$, that is, $m G, m \geq 1$, also admits a super $(b, 1)$-T-antimagic total labeling.

Moreover, for $m$ copies of a graph $G$ which is $(a, 1)-T$ antimagic but is not super, we can derive the following result.

Theorem 3. Let $G$ be an $(a, 1)$-T-antimagic graph of order $p$ and size $q$, where $T$ is a tree. Then $m G, m \geq 1$, is also $a(b, 1)$ T-antimagic graph.

Proof. Let $T$ be a tree of order $k$ and let $G$ be an $(a, 1)-T$ antimagic graph of order $p$ and size $q$ with corresponding labeling $f: V(G) \cup E(G) \rightarrow\{1,2, \ldots, p+q\}$ and the corresponding $T$-weights $a, a+1, a+2, \ldots, a+t-1$.

For every vertex $v$ in $G$, we denote by symbol $v_{i}$ the corresponding vertex in the $i$ th copy of $G$ in $m G$. Analogously, let $u_{i} v_{i}$ be the edge corresponding to the edge $u v$ in the $i$ th copy of $G$ in $m G$.

For $m \geq 1$, we define labeling $g$ of $m G$ as follows:

$$
\begin{array}{cl}
g\left(v_{i}\right)=m(f(v)-1)+i & \text { for } v \in V(G), i=1,2, \ldots, m, \\
g\left(u_{i} v_{i}\right)=m f(u v)+1-i & \text { for } u v \in E(G), i=1,2, \ldots, m
\end{array}
$$

Let $r \in\{1,2, \ldots, p+q\}$. We consider two cases.

Case 1. If the number $r$ is assigned by the labeling $f$ to a vertex of $G$, then the corresponding vertices $v_{i}, i=1,2, \ldots, m$, in the copies $G_{i}$ in $m G$ will receive labels

$$
\begin{gathered}
\left\{g\left(v_{i}\right): g\left(v_{i}\right)=m(r-1)+i, i=1,2, \ldots, m\right\} \\
=\{m(r-1)+1, m(r-1)+2, \ldots, m r\} .
\end{gathered}
$$

Case 2. If the number $r$ is assigned by the labeling $f$ to an edge of $G$, then the corresponding edges $u_{i} v_{i}, i=1,2, \ldots, m$, in the copies $G_{i}$ in $m G$ will have labels

$$
\begin{aligned}
& \left\{g\left(u_{i} v_{i}\right): g\left(u_{i} v_{i}\right)=m r+1-i, i=1,2, \ldots, m\right\} \\
& \quad=\{m r, m r-1, \ldots, m(r-1)+1\} .
\end{aligned}
$$

We can see that the vertex labels and edge labels in $m G$ are not overlapping, and the maximum used label is $m(p+q)$. Thus $g$ is a total labeling.

Analogously as in the proof of Theorem 1 we get that the weight of every subgraph $T_{i}^{j}, i=1,2, \ldots, m, j=1,2, \ldots, t$, under the labeling $g$ attains the value

$$
\begin{aligned}
w t_{g}\left(T_{i}^{j}\right)= & \sum_{v \in V\left(T_{i}^{j}\right)} g(v)+\sum_{u v \in E\left(T_{i}^{j}\right)} g(u v) \\
= & \sum_{v \in V\left(T_{i}^{j}\right)}(m(f(v)-1)+i) \\
& +\sum_{u v \in E\left(T_{i}^{j}\right)}(m f(u v)+1-i) \\
= & m w t_{f}\left(T_{i}^{j}\right)+k(1-m)-1+i
\end{aligned}
$$

and the set of all $T$-weights in $m G$ successively attain consecutive values $m(a-k)+k, m(a-k)+k+1, \ldots, m(a-k+$ $t)+k-1$. Thus the resulting labeling $g$ is a $(b, 1)-T$-antimagic total labeling.

\section{Disjoint Union of Certain Families of Graphs}

In [18], the following results are proved on pathantimagicness of cycles and paths.

Proposition 4 (see [18]). Let $k$ and $n \geq 3$ be positive integers. The cycle $C_{n}$ is a super $(a, 1)-P_{k}$-antimagic for every $k=$ $2,3, \ldots, n$.

Proposition 5 (see [18]). Let $k$ and $n \geq 3$ be positive integers. The path $P_{n}$ is a super $(a, 1)$ - $P_{k}$-antimagic for every $k=$ $2,3, \ldots, n$.

In light of Propositions 4 and 5 and Corollary 2 we immediately obtain the following.

Corollary 6. Let $k, m \geq 1$, and $n \geq 3$ be positive integers. Then $m$ copy of a cycle $C_{n}$, that is, the graph $m C_{n}$, is a super $(a, 1)-P_{k}$-antimagic for every $k=2,3, \ldots, n$. 
Corollary 7. Let $k, m \geq 1$, and $n \geq 3$ be positive integers. Then $m$ copy of a path $P_{n}$, that is, the graph $m P_{n}$, is a super $(a, 1)-P_{k}$-antimagic for every $k=2,3, \ldots, n$.

\section{Conclusion}

In this paper we have shown that the disjoint union of multiple copies of a (super) $(a, 1)$-tree-antimagic graph is also a (super) $(b, 1)$-tree-antimagic. It is a natural question whether the similar result holds also for other differences and other $H$-antimagic graphs. For further investigation we propose the following open problems.

Open Problem 1 . Let $G$ be a (super) $(a, d)-T$-antimagic graph, where $T$ is a tree different from $K_{2}$. For the graph $m G$, determine if there is a (super) $(a, d)$ - $T$-antimagic total labeling, for $d \neq 1$ and all $m \geq 1$.

Open Problem 2. Let $G$ be a (super) $(a, d)$ - $H$-antimagic graph. For the graph $m G$, determine if there is a (super) $(a, d)-H$ antimagic total labeling, for certain values of $d$ and all $m \geq 1$.

\section{Conflict of Interests}

The authors declare that there is no conflict of interests regarding the publication of this paper.

\section{Acknowledgment}

The work was supported by Slovak VEGA Grant 1/0056/15.

\section{References}

[1] A. Gutiérrez and A. Lladó, "Magic coverings," Journal of Combinatorial Mathematics and Combinatorial Computing, vol. 55, pp. 43-56, 2005.

[2] A. Kotzig and A. Rosa, "Magic valuations of finite graphs," Canadian Mathematical Bulletin, vol. 13, pp. 451-461, 1970.

[3] H. Enomoto, A. S. Llado, T. Nakamigawa, and G. Ringel, "Super edge-magic graphs," SUT Journal of Mathematics, vol. 34, no. 2, pp. 105-109, 1998.

[4] M. Bača, F. A. Muntaner-Batle, A. Semaničová-Feňovčíková, and M. K. Shafiq, "On super (a, 2)-edge-antimagic total labeling of disconnected graphs,” Ars Combinatoria, vol. 113, pp. 129-137, 2014.

[5] M. Bača and M. Miller, Super Edge-Antimagic Graphs: A Wealth of Problems and Some Solutions, Brown Walker Press, Boca Raton, Fla, USA, 2008.

[6] R. M. Figueroa-Centeno, R. Ichishima, and F. A. MuntanerBatle, "The place of super edge-magic labelings among other classes of labelings," Discrete Mathematics, vol. 231, no. 1-3, pp. 153-168, 2001.

[7] R. M. Figueroa-Centeno, R. Ichishima, and F. A. MuntanerBatle, "On edge-magic labelings of certain disjoint unions of graphs," The Australasian Journal of Combinatorics, vol. 32, pp. 225-242, 2005.

[8] A. M. Marr and W. D. Wallis, Magic Graphs, Birkhäuser, New York, NY, USA, 2013.

[9] A. Lladó and J. Moragas, "Cycle-magic graphs," Discrete Mathematics, vol. 307, no. 23, pp. 2925-2933, 2007.
[10] T. K. Maryati, A. N. Salman, E. T. Baskoro, J. Ryan, and M. Miller, "On $H$-supermagic labelings for certain shackles and amalgamations of a connected graph," Utilitas Mathematica, vol. 83, pp. 333-342, 2010.

[11] A. N. M. Salman, A. A. G. Ngurah, and N. Izzati, "On (super)edge-magic total labelings of subdivision of stars Sn," Utilitas Mathematica, vol. 81, pp. 275-284, 2010.

[12] A. A. Ngurah, A. N. Salman, and L. Susilowati, " $H$-supermagic labelings of graphs," Discrete Mathematics, vol. 310, no. 8, pp. 1293-1300, 2010.

[13] N. Inayah, A. N. Salman, and R. Simanjuntak, "On $(a, d)-H$ antimagic coverings of graphs," Journal of Combinatorial Mathematics and Combinatorial Computing, vol. 71, pp. 273-281, 2009.

[14] N. Inayah, R. Simanjuntak, A. N. Salman, and K. I. Syuhada, "Super $(a, d)-H$-antimagic total labelings for shackles of a connected graph $H$," The Australasian Journal of Combinatorics, vol. 57, pp. 127-138, 2013.

[15] R. Simanjuntak, M. Miller, and F. Bertault, "Two new (a, d)antimagic graph labelings," in Proceedings of the 11th Australasian Workshop of Combinatorial Algorithm (AWOCA '00), pp. 179-189, Hunter Valley, Australia, July 2000.

[16] K. W. Lih, "On magic and consecutive labelings of plane graphs," Utilitas Mathematica, vol. 24, pp. 165-197, 1983.

[17] A. Ahmad, M. Bača, M. Lascsáková, and A. SemaničováFeňovčíková, "Super magic and antimagic labelings of disjoint union of plane graphs," Science International, vol. 24, no. 1, pp. 21-25, 2012.

[18] A. Semaničová-Feňovčíková, M. Bača, M. Lascsáková, M. Miller, and J. Ryan, "Wheels are cycle-antimagic," Electronic Notes in Discrete Mathematics, In press. 


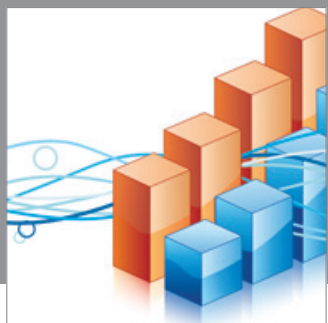

Advances in

Operations Research

mansans

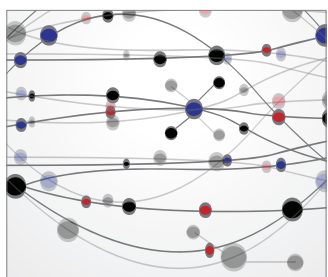

The Scientific World Journal
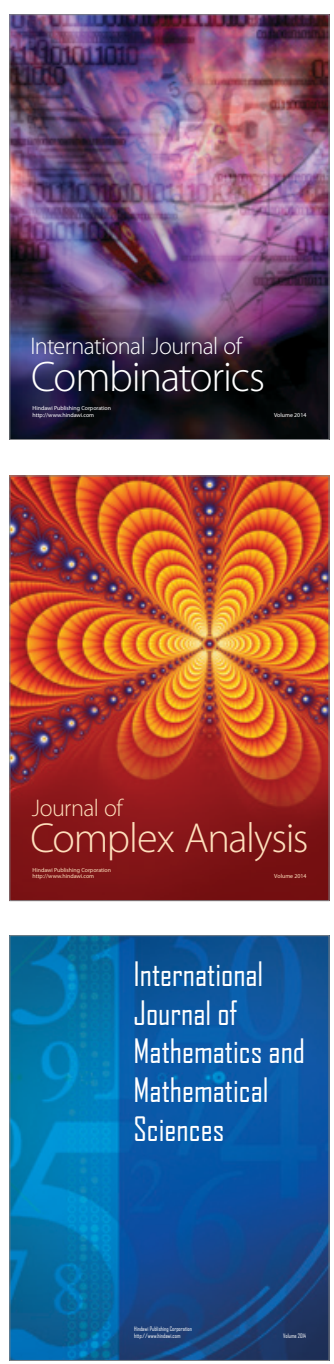
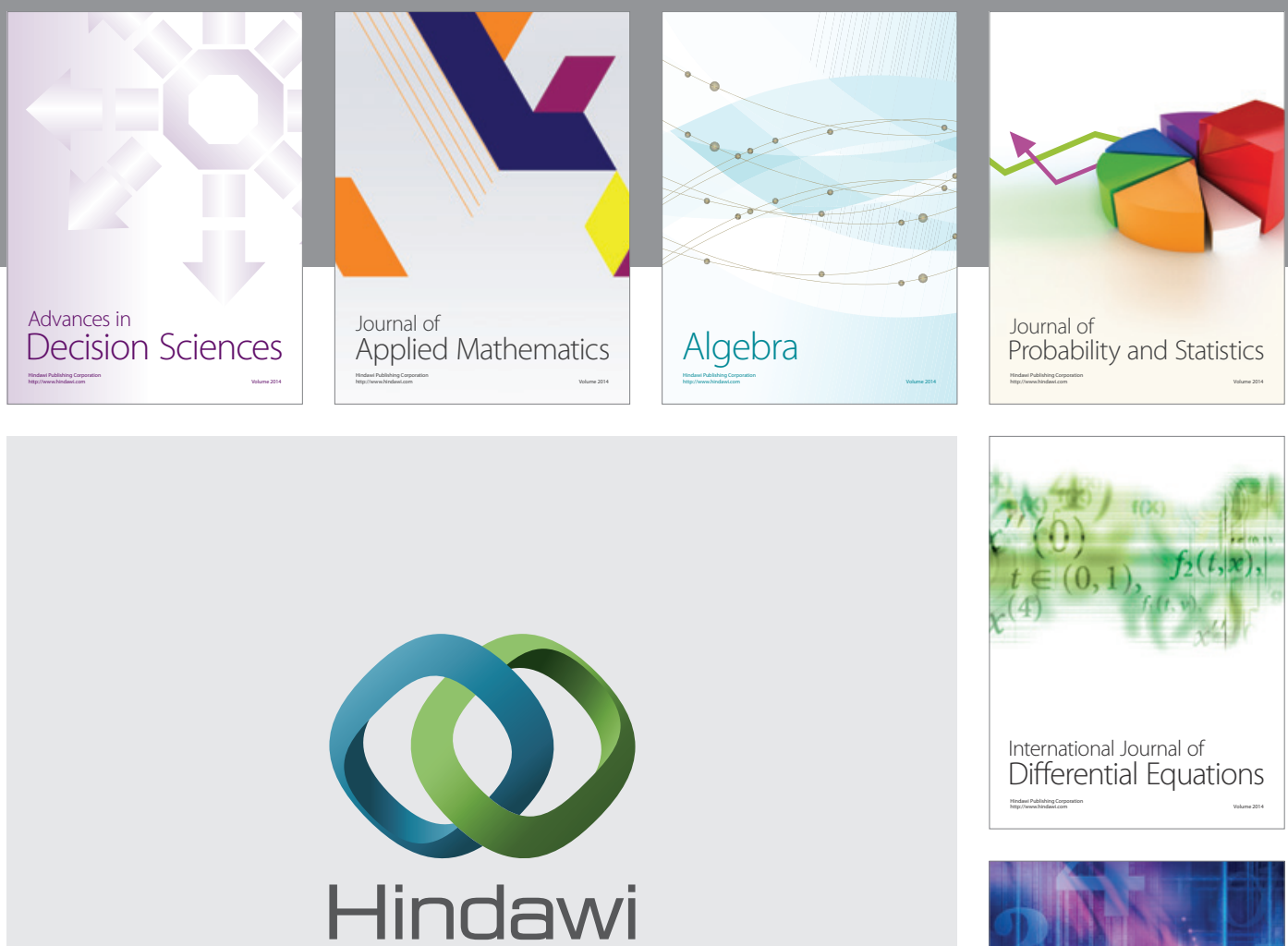

Submit your manuscripts at http://www.hindawi.com
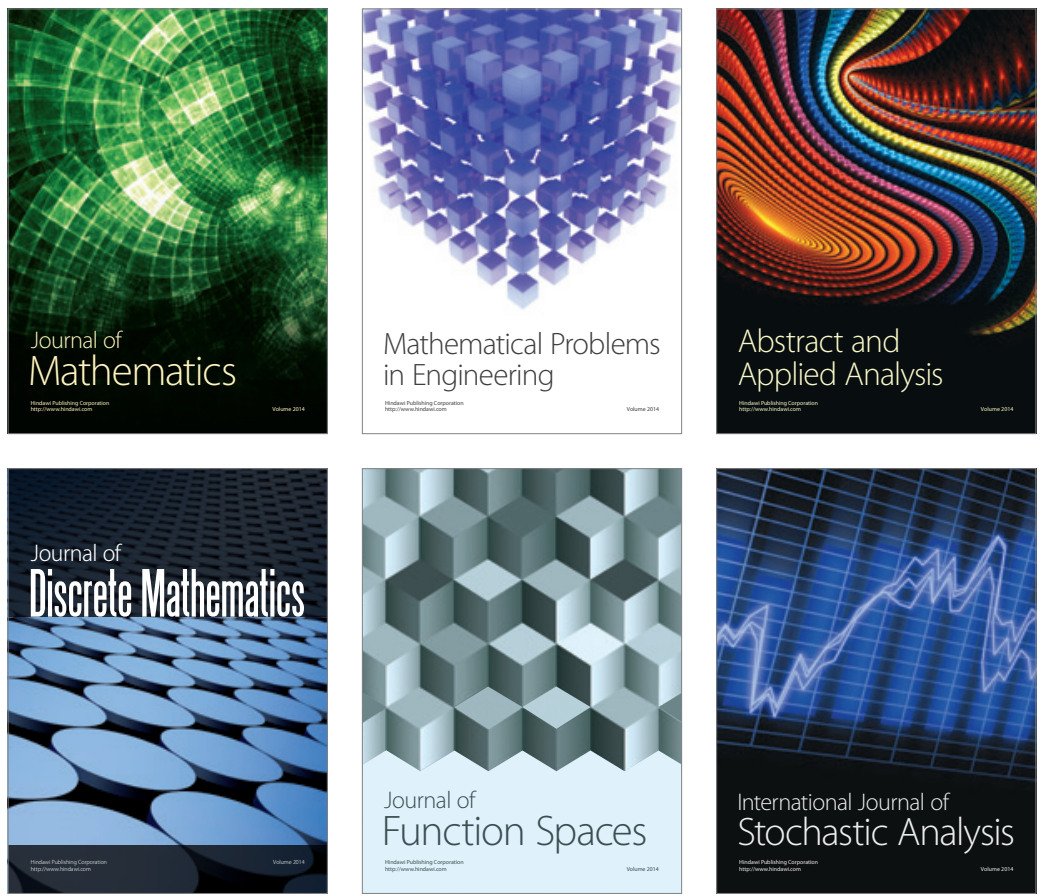

Journal of

Function Spaces

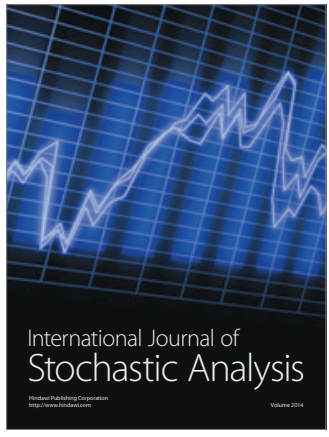

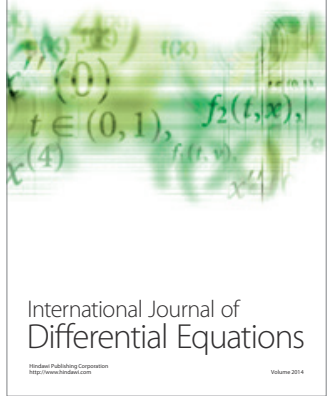
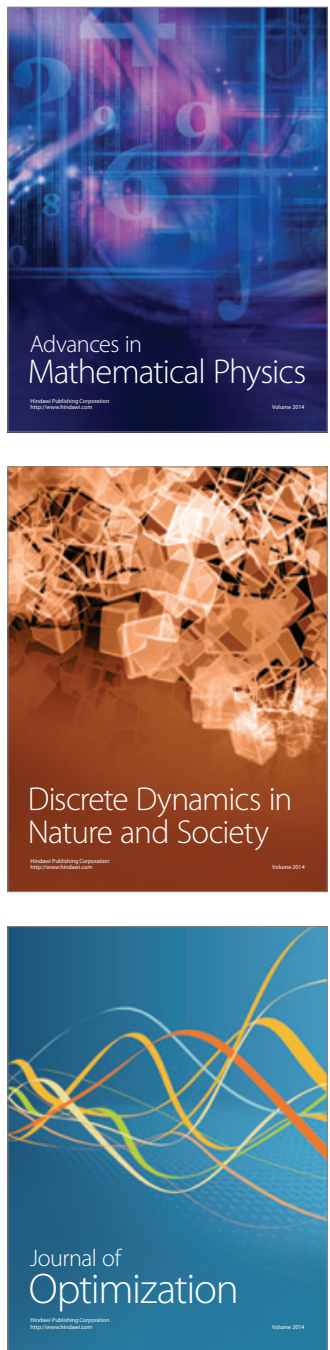